\title{
Matrix Stiffness Corresponding to Strictured Bowel Induces a Fibrogenic Response in Human Colonic Fibroblasts
}

\author{
Laura A. Johnson, B.S. ${ }^{1}$, Eva S. Rodansky, M.S. ${ }^{1}$, Kay L. Sauder, B.S. ${ }^{1}$, Jeffrey C. Horowitz, \\ M.D. ${ }^{2}$, Justin D. Mih, Ph.D. ${ }^{3}$, Daniel J. Tschumperlin, Ph.D. ${ }^{3}$, and Peter D. Higgins, M.D, \\ Ph.D., M.Sc. ${ }^{1,}$ \\ ${ }^{1}$ Division of Gastroenterology and Hepatology, Internal Medicine, University of Michigan, Ann \\ Arbor, MI, United States \\ ${ }^{2}$ Division of Pulmonary and Critical Care Medicine, University of Michigan, Ann Arbor, MI, United \\ States \\ ${ }^{3}$ Molecular and Integrative Physiological Sciences, Department of Environmental Health, Harvard \\ School of Public Health, Boston, MA, United States
}

\begin{abstract}
Background-Crohn's disease is characterized by repeated cycles of inflammation and mucosal healing which ultimately progress to intestinal fibrosis. This inexorable progression towards fibrosis suggests that fibrosis becomes inflammation-independent and auto-propagative. We hypothesized that matrix stiffness regulates this auto-propagation of intestinal fibrosis.
\end{abstract}

\begin{abstract}
Methods-The stiffness of fresh ex vivo samples from normal human small intestine, Crohn's disease strictures, and the unaffected margin were measured with a microelastometer. Normal human colonic fibroblasts were cultured on physiologically normal or pathologically stiff matrices corresponding to the physiological stiffness of normal or fibrotic bowel. Cellular response was assayed for changes in cell morphology, a-smooth muscle actin (aSMA) staining, and gene expression.
\end{abstract}

Results-Microelastometer measurements revealed a significant increase in colonic tissue stiffness between normal human colon and Crohn's strictures as well as between the stricture and adjacent tissue margin. In Ccd-18co cells grown on stiff matrices corresponding to Crohn's strictures, cellular proliferation increased. Pathologic stiffness induced a marked change in cell morphology and increased aSMA protein expression. Growth on a stiff matrix induced fibrogenic gene expression, decreased matrix metalloproteinase and pro-inflammatory gene expression, and was associated with nuclear localization of the transcriptional cofactor MRTF-A.

Conclusions-Matrix stiffness, representative of the pathological stiffness of Crohn's strictures, activates human colonic fibroblasts to a fibrogenic phenotype. Matrix stiffness affects multiple pathways suggesting the mechanical properties of the cellular environment are critical to fibroblast function and may contribute to autopropagation of intestinal fibrosis in the absence of inflammation, thereby contributing to the intractable intestinal fibrosis characteristic of Crohn's disease.

\footnotetext{
*Corresponding author: Peter Higgins, MD, PhD, MSc (CRDSA), Division of Gastroenterology and Hepatology, Department of Internal Medicine, University of Michigan Medical Center, Medical Science Research Building One, 1150 West Medical Center Drive, Ann Arbor, MI 48109-5682, Phone: 734-647-2964, Fax: 734-763-2535, phiggins@ med.umich.edu.

Publisher's Disclaimer: This is a PDF file of an unedited manuscript that has been accepted for publication. As a service to our customers we are providing this early version of the manuscript. The manuscript will undergo copyediting, typesetting, and review of the resulting proof before it is published in its final citable form. Please note that during the production process errors may be discovered which could affect the content, and all legal disclaimers that apply to the journal pertain.
} 


\section{Keywords}

Crohn's disease; inflammatory bowel disease; fibrosis; fibroblast; extracellular matrix; stiffness

\section{INTRODUCTION}

Crohn's disease (CD) is characterized by repeated cycles of intestinal inflammation (flares) and healing. During the wound healing phase, the intestinal architecture including the mucosa, epithelium, subepithelium, and basement membrane is reconstituted (1). However, repeated cycles of inflammation and repair ultimately produce intestinal fibrosis, strictures, and stenosis necessitating surgical intervention for the majority of CD patients $(2,3)$. Current therapies control inflammation and improve symptoms, yet do not alter the natural history of $\mathrm{CD}$ and the development of intestinal fibrosis suggesting fibrosis becomes autopropagative (4). Supporting this concept of auto-propagation, we recently demonstrated in a murine model of intestinal inflammation and fibrosis that intestinal fibrosis can progress despite suppression of inflammation (5).

Normal wound healing is mediated by myofibroblasts which are postulated as the major contributor to intestinal fibrosis (6). Myofibroblasts mediate tissue repair by producing components of, and physically contracting the extracellular matrix (ECM), to facilitate wound closure (7-9). However, excessive ECM production and wound contraction by myofibroblasts produces fibrosis in multiple organ systems including heart, lung, liver, skin, and intestine $(1,10,11)$.

In Crohn's disease, fibrotic strictures are characterized by excessive ECM deposition and a pathological persistence of activated fibroblasts (12). In a rat model of colitis, we have shown that intestinal fibrosis is associated with increased tissue stiffness $(13,14)$. Until recently, increased tissue stiffness has been described as a consequence of, and not a contributing factor to, tissue fibrosis (15). However, recent work demonstrates the importance of mechano-regulation in ECM remodeling $(16,17)$. Mechanical stress induces changes in both fibroblast morphology and function from a quiescent non-proliferative to an activated, ECM -secreting phenotype (18).

We hypothesized that matrix stiffness mimicking the stiffness of CD strictures would induce human fibroblasts to develop an activated, fibrogenic phenotype which may contribute to the autopropagation of fibrosis.

\section{MATERIALS and METHODS}

\section{Human intestinal tissue acquisition}

Fresh, non-fixed human tissue from subjects undergoing elective resection of symptomatic small intestinal strictures or normal small bowel tissue from elective bariatric surgery was obtained from the University of Michigan Medical Center. The Institutional Review Board of the University of Michigan approved the study protocol. Participants provided signed informed consent prior to surgery. In addition, formalin-fixed paraffin embedded (FFPE) histological sections from these human subjects were acquired from the University of Michigan, Department of Pathology specimen library.

\section{Measurement of human intestinal stiffness}

To determine the stiffness of both the normal and Crohn's diseased human intestinal tissue, a $1 \mathrm{~cm}^{2}$ section of fresh, non-fixed normal bowel, CD stricture, or the unaffected margin was measured using a microelastometer (MicroElastometer, Artann Laboratories, West 
Trenton, NJ, USA). Using a small piston, an increasing force is applied to the tissue which rests on a pressure sensitive stage. By measuring the vertical tissue displacement and applied force, the stress (force per unit area) and strain (compression) is measured and graphed. The resulting stress-strain curves are used to calculate the elastic modulus (Young's Modulus) which reflects the stiffness of a material. Young's Modulus was calculated using the following equation (Figure 1B): Young's Modulus $(E)=$ stress $(\sigma)$ divided by strain $(\varepsilon)$ where $\mathrm{F}$ is the applied force (in Newtons) from the microelastometer stamp, calculated as the change in tissue weight divided by the contact area of the microelastometer piston and strain $(\varepsilon)$ was calculated from the change in sample height. For each tissue sample, three measurements from $1 \mathrm{~cm} \times 1 \mathrm{~cm}$ regions were used to calculate tissue stiffness.

\section{RNA isolation from FFPE tissues}

RNA was isolated from two 10 um full-thickness tissue sections of formalin-fixed paraffin embedded (FFPE) human intestinal specimens using the Qiagen RNA FFPE kit (Qiagen, Valencia, CA) in accordance with the manufacturer's instructions. cDNA was synthesized using the First Strand Synthesis kit (Invitrogen, Carlsbad, CA) according to manufacturer's protocol.

\section{Preparation of stiffness substrates}

Collagen-coated polyacrylamide gels corresponding to elastic moduli of $2.6 \mathrm{kPa}$ to $28 \mathrm{kPa}$ were generated using varying ratios of $40 \%$ acrylamide to $2 \%$ bisacrylamide (Bio-Rad, Hercules, CA) (19-21). Specifically, an aqueous solution of $0.10 \%$ ammonium persulfate (Bio-Rad), 0.15\% TEMED (Bio-Rad), 40\% acrylamide solution was supplemented with $0.01 \%, 0.02 \%, 0.08 \%$, or $0.16 \%$ bisacrylamide. The acrylamide gels were polymerized on a $\mathrm{NaOH}$ treated, aminosilanated (3-aminopropyltriethoxysilane), and glutaraldehyde treated round glass coverslip. $10 \mathrm{ml}$ of each acrylamide/bisacrylamide solution was filter-sterilized and pipetted unto a chlorosilanated glass surface treated with dichlorordimethylsilane (DCDMS) and a treated coverslip was inverted onto the acrylamide/biacrylamide solution. The acrylamide substrate was allowed to polymerize for 10 minutes between the two surfaces and transferred to a 6-well tissue culture plate containing sterile PBS. As determined by a series of stability experiments (data not shown), the acrylamide gels were stable for at least 1 month. For all experiments, gels were used within a month. Prior to seeding with colonic fibroblasts, the acrylamide gels were collagen-coated as follows: 0.2 $\mathrm{mg} / \mathrm{ml}$ of sulfo-SANPAH (Thermo Scientific, Rockford, IL) was added to each well containing the acrylamide gel-coated cover slip and UV crosslinked at a wavelength of 254 $\mathrm{nm}$ in a Stratagene UV crosslinker oven (Stratagene, La Jolla, CA) at a 3-inch distance from the UV source for 10 minutes. The gels were coated with $0.2 \mathrm{mg} / \mathrm{ml}$ of rat tail collagen I (BD Biosciences, Bedford, MA) overnight at $37^{\circ} \mathrm{C}$ with gentle agitation. Excess collagen was removed by several washes with sterile PBS. Gels were UV sterilized for 30 minutes prior to seeding with colonic fibroblasts. The elasticity of the gels was measured with a microelastometer as described above.

Previous work determined tissue elasticity of $\sim 1 \mathrm{kPa}$ for normal and $\sim 4 \mathrm{kPa}$ for fibrostenotic tissue, calculating strain from the first $30 \%$ of the strain curve (14). However tissue mechanical properties are heterogeneous with non-linear elastic properties at relatively low strains (i.e. force is not proportional to deformation). Homogenous substrates such as polyacrylamide gels are linear over the range of force generated by the microelastometer (22). (Figure 1A) Therefore to generate stiffness gels directly comparable to the human ex vivo tissue while compensating for the pre-loading and non-linearity of tissue, we calculated the Young's Modulus for human tissue from the slope of the first to the second inflection points on the strain curve (50-60\% of the strain value). (Figure 1C) While the calculated elastic modulus is higher than previously reported, this method allows for a direct 
comparison between a homogenous matrix (polyacrylamide gel) with linear stress-strain and a non-linear matrix such as tissue, thus facilitating modeling human tissue stiffness with in vitro stiffness polyacrylamide gels.

\section{Cells and cell culture}

Human colonic fibroblast Ccd-18Co cells (CRL-1459) were obtained from ATCC (Bethesda, MD). Cells were cultured in a-MEM (Invitrogen, Carlsbad, CA) supplemented with $10 \%$ fetal bovine serum and sub-cultured weekly. Primary colonic myofibroblasts (CMF cells), a gift from Don Powell or human intestinal fibroblasts (HIF) a gift from Florian Rieder were cultured in a-MEM, supplemented with $10 \%$ fetal bovine serum. Lowpassage number cells were seeded at $1 \times 10^{5}$ cells $/ \mathrm{ml}$ on 6 -well plates containing acrylamide gels of 2.6, 4.3, 16, or $28 \mathrm{kPa}$ elastic moduli. Cells were allowed to attach to the matrix for 4 hours prior to transfer of the coverslip and hydrogel to a new 6-well plate to avoid potential paracrine signaling from cells adhering to the plastic surrounding the coverslip. After 24 hours, cells were photographed using an Olympus (inverted) light microscope and harvested for RNA.

\section{Cell proliferation assay}

Cell proliferation was determined using the MTT assay as follows: Low-passage number cells were seeded at $2 \times 10^{5}$ cells $/ \mathrm{ml}$ on 24 -well plates containing acrylamide gels of 2.6, 4.3, 16 , or $28 \mathrm{kPa}$ elastic moduli. Cells were allowed to attach to the matrix for 4 hours prior to transfer of the coverslip and hydrogel to a new 24-well plate containing serum-free media. After 4 or 24 hrs, the media was replaced with media containing MTT [3-(4,5dimethylthiazol-2-yl)-2,5-diphenyltetrazoliumbromide]. Cells were incubated in MTT media for an additional $4 \mathrm{hr}$ then solubilized with acidified isopropanol for $15 \mathrm{~min} .200 \mu \mathrm{l}$ of the MTT reaction was transferred to a 96-well plate and the absorbance was determined using a Syngery 2 microplate reader (BioTek, Winooski, VT) at 570nm.

\section{Real-time Quantitative PCR}

RNA was extracted from cultured cells using the RNeasy kit (Qiagen, Valencia, CA). RNAs were treated with RNase-free DNase prior to cDNA synthesis using the First Strand Synthesis kit (Invitrogen, Carlsbad, CA) according to manufacturer's protocol. The analysis of gene expression of both human FFPE intestinal samples and cultured cells was determined by quantitative real-time PCR (QPCR) of collagenIA1 (colIA1), myosin light chain kinase (MYLK), matrix metallopeptidases 1, 3, 10 (MMP1, MMP3, MMP10), IL-1 $\beta$, COX2 (PTGS2), TNFa, MKL1 (MRTF-A) genes and GAPDH was performed with the TaqMan gene expression assays (ABI, Foster City, CA). QPCR was performed using a Stratagene Mx3000P real-time PCR system (Stratagene, La Jolla, CA). Cycling conditions were $95^{\circ} \mathrm{C} 10$ minutes, followed by 40 cycles of $95^{\circ} \mathrm{C} 15$ seconds and $62^{\circ} \mathrm{C} 60$ seconds. $\Delta \Delta \mathrm{Ct}$ were calculated from GAPDH expression.

\section{Casein Zymography}

Casein zymography was performed as follows: $20 \mathrm{ul}$ of culture supernatants were diluted in 2x sample buffer ( $0.125 \mathrm{mM}$ Tris, $20 \%$ glycerol, $4 \%$ (wt/vol) SDS, $0.1 \%$ bromophenol blue) and electrophoresed on a 12\% Ready Gel Zymogram (Biorad, Hercules, CA) at 125V. After electrophoresis, the gels were washed twice for $30 \mathrm{~min}$ in $25 \%$ (wt/vol)Triton X-100 at room temperature followed by an overnight incubation at $37^{\circ} \mathrm{C}$ in developing buffer $(50 \mathrm{mM}$ Tris$\mathrm{HCl}, 0.2 \mathrm{M} \mathrm{NaCl}, 5 \mathrm{mM} \mathrm{CaCl} 2,0.02 \%$ (wt/vol) Birj-35, and $5 \mathrm{mM}$ PMSF pH 8.0) with gentle shaking. The gels were then stained with $0.5 \%$ (wt/vol) Coomassie Blue R-250 for 1$2 \mathrm{~h}$ and destained in 10\% (vol/vol) acetic acid and 50\% (vol/vol) methanol. MMP-3 
proteolytic activity was detected by clear bands indicating the lysis of the casein substrate.

Gels were digitally photographed and the bands were quantified using ImageJ.

\section{Reagents}

All reagents unless otherwise noted were obtained from Sigma (St. Louis, MO).

\section{Immunofluorescence imaging}

Expression of activated myofibroblast markers was analyzed by confocal immunofluorescence microscopy using the Olympus FluoViewTM FV500/IX system (Olympus America, Center Valley, PA) at the University of Michigan Microscopy and Image Analysis Laboratory. Ccd-18Co cells were seeded onto collagen-coated polyacrylamide gels (ranging from 2.6 to $28 \mathrm{kPa}$ ) attached to glass coverslips. After 24 hours, gels were rinsed with PBS, then were fixed with $4 \%$ paraformaldehyde (Electron Microscopy Sciences, Hatfield, PA) in PBS for 5 minutes, followed by permeabilization with $0.2 \%$ Triton X-100 (LabChem, Pittsburgh, PA) for 15 minutes. Gels were rinsed 3 times with PBS, then were pre-blocked with SFX signal enhancer (Invitrogen, Carlsbad, CA), and blocked with 20\% goat serum (Invitrogen, Carlsbad, CA). For visualization of focal adhesions, the gels were incubated for 2 hours at room temperature with mouse anti-vinculin primary antibody (Sigma, St. Louis, MO) at 1:250 in PBS/0.1\% Triton. The gels were rinsed three times with PBS/0.1\% Triton, followed by incubation with Alexa 555-conjugated goat anti-mouse secondary antibody (Molecular Probes, Eugene, OR) for 30 minutes, at room temperature, in PBS/0.1\% Triton. Gels were washed 6 times, followed by incubation with phalloidin (Sigma, St. Louis, MO) at 1:100 for 2 hours, for visualization of actin stress fibers. Cells were co-stained with 4, 6' diamidino-2-phenylindole (DAPI), (Molecular Probes, Eugene, OR) to visualize nuclei. The gels were mounted with ProLong Gold mounting medium (Invitrogen, Carlsbad, CA) prior to imaging by confocal immunofluorescence microscopy.

For MRTF-A visualization, the gels were incubated for 2 hours at room temperature with rabbit anti-MRTFA primary antibody (Santa Cruz Biotechnology, Santa Cruz, CA) at 1:50 in PBS/0.1\% Triton. The gels were rinsed three times with PBS/0.1\% Triton, followed by incubation with Alexa 555-conjugated goat anti-rabbit secondary antibody (Molecular Probes, Eugene, OR) for 30 minutes, at room temperature, in PBS/0.1\% Triton. Gels were washed 6 times, followed by staining with phalloidin and DAPI as described above.

\section{Statistical analysis}

Statistical differences were determined by a two-sided, unpaired Student's t-test. Results with a $p$ value of $<0.05$ were considered statistically significant.

\section{RESULTS}

\section{Intestinal stiffness and expression of extracellular matrix and matrix remodeling genes are increased in Crohn's strictures compared to the unaffected margin or normal human intestine}

Crohn's strictures are qualitatively firm and thick compared to normal bowel when palpated and are quantitatively stiffer by both mechanical and ultrasound elasticity measurements (14). To model human intestinal stiffness in vitro, we first measured the stiffness of normal human intestine using fresh ex vivo normal human small intestine from bariatric surgical cases compared to surgically resected Crohn's strictures and the adjacent margin using a microelastometer. As calculated from the linear portion of the strain stiffness curve, normal intestine and the unaffected margin from Crohn's resected bowel were indistinguishable in stiffness and highly compliant with a median Young's Modulus of 2.9 or $2.6 \mathrm{kPa}$ 
respectively. (Figure 1D) In contrast, Crohn's strictures were nearly 6-fold less compliant $(16.7 \mathrm{kPa}$ vs. $2.9 \mathrm{kPa}, \mathrm{p}<0.001)$ compared to normal tissue and the unaffected margin (16.7 $\mathrm{kPa} v$ s. $2.6 \mathrm{kPa}, \mathrm{p}<0.01)$.

Strictures are characterized by excess deposition of collagen and matrixmetalloproteinase (MMP) mediated extracellular matrix remodeling. In Crohn's strictures, Collagen IA1 gene expression was increased in full-thickness tissue sections from Crohn's strictures compared to full-thickness sections from either normal bowel (27-fold, $\mathrm{p}=0.047$ ) or the unaffected margin (2-fold, $\mathrm{p}=0.03$ ) (Figure 2A). MMP-3 gene expression was dramatically increased compared to either normal bowel $(>1,000$-fold, $\mathrm{p}=0.018)$ or the unaffected margin $(>1,000$ fold vs. 5-fold, $\mathrm{p}=0.05$ ) (Figure 2B). Expression of MMP-3 and collagenIA1 did not differ between normal bowel and the unaffected margin surrounding the stricture.

In the colon, mucosal barrier integrity and wound healing are mediated by myosin light chain kinase (MLCK or MYLK) $(23,24)$. Increased MYLK expression has been linked to inflammatory bowel disease, including Crohn's disease (23). In human stricture tissue, MYLK gene expression varied widely among stricture samples but trended higher in Crohn's strictures compared to normal bowel $(19.7$-fold, $p=0.068)$ and the unaffected margin (19.7-fold vs. 2.1-fold $\mathrm{p}=0.074$ ) (Figure 2C).

Concurrent with the induction of fibrogenic and matrix remodeling genes, inflammatory genes including IL- $1 \beta$ and PTGS2 (which encodes the COX-2 enzyme) were increased in strictured tissue. IL-1 $\beta$ was induced 190 -fold compared to normal bowel $(p=0.046)$ with a trend towards higher expression between the stricture and the unaffected margin (Figure 2D). Similarly, PTGS2 (COX-2) expression was significantly induced nearly 280 -fold in the strictured tissue compared to normal bowel $(\mathrm{p}=0.011)$ with a trend towards higher expression in the stricture compared to the unaffected margin (279-fold vs. 8.2 fold, $\mathrm{p}=$ 0.057) (Figure 2E). In summary, Crohn's strictures are physiologically stiffer than either normal bowel or their surgical margins, with a gene expression profile indicative of active wound healing with concurrent fibrosis and inflammation.

\section{Increasing matrix stiffness corresponding to strictured colon alters fibroblast morphology, actin stress fiber formation and focal adhesions, while promoting fibroblast proliferation}

In Crohn's disease, excessive ECM deposition is associated with pathological persistence of activated myofibroblasts (12). Though fibroblast activation classically has been described as causative of tissue stiffness, in other tissues matrix stiffness alone activates fibroblasts (15, 17). As previously demonstrated by our group, both fibrosis (characterized by excessive collagen deposition) as well as inflammation (tissue edema), can contribute to tissue stiffness (14). Given the mixed fibrotic/inflammatory gene expression profile produced by multiple cell types present in the human ex vivo tissue, we employed a reductionist model to segregate fibrosis from confounding effects of inflammation and the host immune system.

To determine if matrix stiffness alone could activate intestinal fibroblasts, normal human colonic fibroblasts (Ccd-18co cells) were cultured for 24 hours on a series of collagencoated acrylamide matrices corresponding to normal (2.6, $4.3 \mathrm{kPa})$ or strictured (16-28 $\mathrm{kPa})$ bowel. On physiologically soft matrices of $2.6-4.3 \mathrm{kPa}$, characteristic of normal bowel, Ccd-18co fibroblasts exhibited a rounded, quiescent morphology (Figure 3A, left panel). However, Ccd-18co fibroblasts cultured on physiologically stiff matrices of $16-28 \mathrm{kPa}$, corresponding to Crohn's strictures, developed a stellate morphology, characterized by multiple dendritic processes (Figure 3A, left panel). To exclude potential stimulatory effects of increased bis-acrylamide present in the stiff matrix, Ccd-18co cells were cultured on 4.3 $\mathrm{kPa}$ stiffness gels to which increasing amounts of bis-acrylamide were added. Excess bisacrylamide did not cause changes in cell morphology in the cells cultured on the soft 
substrate even at concentrations 7-fold higher than the amount of bis-acrylamide used in the stiff substrates (Supplemental Figure 1). This stiffness-induced stellate morphology was associated with noted changes in the cytoskeletal architecture as demonstrated by increased actin filament staining, and development of mature focal adhesions (Figure 3, middle panel and insets). This morphological transition was accompanied by a concurrent increase in cell number as determined by direct counting and the MTT proliferation assay. Cell number significantly increased by 2.7 -fold between physiologically soft and stiff matrices $(\sim 4.3 \mathrm{kPa}$ vs. $16 \mathrm{kPa}, \mathrm{p}<0.001$ ) (Figure 4A). Cell proliferation was significantly higher at high matrix stiffness of $16 \mathrm{kPa}(\mathrm{p}=0.019)$ and $28 \mathrm{kPa}(\mathrm{p}=0.009)$ (Figure 4B). Similar morphological responses and a 2 -fold increase in cell proliferation ( $2.6 \mathrm{kPa}$ vs. $28 \mathrm{kPa}, \mathrm{p}=0.03)$ were observed in primary human colonic fibroblasts and human intestinal fibroblasts (Supplemental Figures 2 and 3).

\section{Increasing matrix stiffness induces myosin light chain kinase (MYLK) and represses matrix turnover gene expression}

Colonic fibroblasts respond to increased matrix stiffness by transitioning to an activated, potentially fibrogenic morphology with increased actin (stress fiber staining) and formation of focal adhesions. Stress fiber contraction is mediated by myosin light chain kinase (MLCK or MYLK) which allows myosin II to bind actin filaments in cytoskeletal stress fibers transferring the contractile forces to the ECM via focal adhesions (25). As stiffness increases, the expression of MYLK (the gene encoding the MLCK protein) was induced $~ 2-$ fold at high elastic moduli $(16,28 \mathrm{kPa}$ compared to $2.6 \mathrm{kPa})$ with a trend towards increased MYLK expression at the transition point between $4.3 \mathrm{kPa}$ and $16 \mathrm{kPa}$ (Figure 5A). Though modest, this stiffness-induced expression may have disproportionately profound effects as very small changes in MYLK expression have been reported to lead to notable dysfunction in a number of disease states (26).

While increased ECM deposition is characterized by increased expression of matrix structural genes, ECM remodeling is also regulated by expression of potent matrix degrading proteins including matrix metalloproteinases (MMP)(27). During intestinal wound healing, MMP-1, MMP-3, and MMP-10 are upregulated (28, 29). To determine the effect of increasing matrix stiffness on matrix proteolytic gene transcription, the expression of matrix metalloproteinases MMP1 (collagenase 1), MMP-3 (stromelysin-1), and MMP- 10 (stromelysin-2) was determined by QRT-PCR. In Ccd-18co colonic fibroblasts grown on increasing matrix stiffnesses, MMP-3 expression was repressed by increasing substrate stiffness (Figure $5 \mathrm{~B})$. This 0.5 -fold repression was significant $(\mathrm{p}=0.03)$ with a modest increase in stiffness from at $2.3 \mathrm{kPa}$ to $4.3 \mathrm{kPa}$ and accentuated by further increases in matrix stiffness (5-fold at $16 \mathrm{kPa}$ and 9-fold at $28 \mathrm{kPa}$ ( $\mathrm{p}<0.001$ ) (Figure 5B). MMP-10 showed a trend for decreased expression with increasing matrix stiffness that did not reach statistical significance (data not shown). To test whether transcriptional repression of MMP-3 had functional significance, casein gel zymography was performed to ascertain MMP-3 proteolytic activity in response to matrix stiffness. As demonstrated in culture supernatants from Ccd-18co cells, MMP-3 proteolytic activity was repressed at physiologically high stiffness (Figure 6A). In addition, this proteolytic activity decreased over time, with a 5-fold ( $\mathrm{p}<0.001)$ difference between the soft $4.3 \mathrm{kPa}$ and stiff $28 \mathrm{kPa}$ substrates (Figure 6B).

\section{Increasing matrix stiffness represses pro-inflammatory gene expression}

During wound healing, inflammatory cytokines, specifically IL-1 $\beta$, trigger matrix catabolism through activation of matrix metalloproteinases including MMP-1 and MMP-3 (29-31). Once wound healing resolves, myofibroblasts undergo apoptosis which is mediated, in part, by IL-1 $\beta$ (32-34). Since Ccd-18co colonic fibroblast cell density increases 
with increasing matrix stiffness while MMP gene expression is concurrently repressed, we determined if increasing matrix stiffness represses pro-inflammatory gene expression including IL-1 $\beta$.

IL-1 $\beta$ is repressed 3-5-fold at high matrix elastic moduli of 16 and $28 \mathrm{kPa}$ ( $\mathrm{p}<0.001$ vs. 2.3 $\mathrm{kPa}$ ) (Figure 5D). In intestinal myofibroblasts, IL-1 $\beta$ induces cyclooxygenase-2 (COX-2) which mediates both chronic and acute intestinal inflammation $(35,36)$. Prostaglandin E2 $\left(\mathrm{PGE}_{2}\right)$, a product of $\mathrm{COX}-2$, represses fibroblast proliferation and activation while increasing sensitivity to apoptosis $(37,38)$. In dermal fibroblasts, COX-2 induction is mediated by an autocrine loop involving IL- $1 \beta$ (39). In Ccd-18co fibroblasts, increasing matrix stiffness dramatically represses the expression of the PTGS2 (prostaglandinendoperoxide synthase 2) gene which encodes the COX-2 enzyme. In Ccd-18co cells, PTGS2 expression was attenuated $\sim 3$ to 6 -fold at 16 and $28 \mathrm{kPa}$ compared to $2.3 \mathrm{kPa}$ ( $\mathrm{p}<$ 0.001 )(Figure 5E). However, the expression of TNFa, another inflammatory cytokine, was unaffected by matrix stiffness (data not shown). Overall, the repression of IL- $1 \beta$ and IL-1 $\beta$ responsive inflammatory genes to matrix stiffness suggests a potential role of IL- $1 \beta$ pathways in the fibroblast cellular response to matrix stiffness.

\section{Increasing matrix stiffness induces aSMA protein expression in colonic fibroblasts}

Fibroblast activation, characterized by increased contractile ability which is essential for wound healing and closure, is identified and enhanced by expression of a-smooth muscle actin (aSMA)(40). While other groups have shown that fibroblasts are activated by stiffnesses over a broad range of 40-fold to 64-fold in lung, we examined the specific 8 -fold transition point between normal $(4.3 \mathrm{kPa})$ and fibrotic $(28 \mathrm{kPa})$ colon $(41,42)$. aSMA protein expression was nearly undetectable in human colonic fibroblasts cultured on the physiologically compliant substrate (Figure 7A). However increased matrix stiffness induced aSMA protein expression $>3$-fold $(\mathrm{p}=0.03)$ as demonstrated in Figure 7B.

\section{Fibroblast activation by increased matrix stiffness is associated with increased MKL1 transcription and MRTF-A nuclear localization}

aSMA promoter activity is enhanced by mechanical force, which has been reported as mediated by the transcriptional cofactor MRTF-A (myocardin-related transcription factor, also identified as MKL1, MAL, or BSAC) (43). MRTF shuttling from the cytoplasm to the nucleus transmits cytoskeletal signals regulating a number of cellular processes including growth and differentiation (44). In Ccd-18co cells cultured on the $28 \mathrm{kPa}$ matrix compared to the soft $4.3 \mathrm{kPa}$ matrix, MKL1 gene expression was induced 2-fold ( $\mathrm{p}<0.001$ )(Figure 8C). Additionally, substrate stiffness affected MRTF-localization. In Ccd-18co cells cultured on the $4.3 \mathrm{kPa}$ compliant substrate, MRTF-A remained located in the cytoplasm (Figure 8A). In contrast, growth on the stiff $28 \mathrm{kPa}$ substrate promoted MRTF-A translocation to the nucleus (Figure 8B). In cells cultured on the stiff matrix, MRTF-A nuclear accumulation increased over time from $1 \mathrm{hr}$ to $24 \mathrm{hr}$ while the soft matrix MRTF-A localization remained cytoplasmic, even at $24 \mathrm{hr}$ (Figure 8A). Similar nuclear translocation in response to high matrix stiffness was observed in primary human colonic fibroblasts (Supplemental Figure 4).

\section{DISCUSSION}

Intestinal fibrosis is a key unsolved complication of Crohn's disease (CD). While current disease management controls inflammation, reducing flares and symptoms, underlying fibrostenotic disease often smolders unabated, producing profound long-term complications (45-48). Indeed, recent evidence in a mouse model demonstrated that intestinal fibrosis, once initiated, may become autopropagative despite the eradication of inflammation (5). 
Activated colonic myofibroblasts function as key mediators of fibrosis and tissue stiffness by two mechanisms: 1) excessive extracellular collagen production which stiffens the extracellular matrix (ECM) and 2) active contraction of the ECM, which exerts additional mechanical force on the matrix $(9,18,40,49)$. Classically, tissue stiffness has been described as an outcome, not a propagator of tissue fibrosis. However, a growing body of evidence in other organ systems has demonstrated the role of mechano-regulation in fibroblast activation, ECM remodeling, and subsequent fibrosis (16-18).

Intestinal fibrosis is characterized by increased tissue stiffness, distinguishable from both normal bowel and edematous bowel by mechanical measurement and ultrasound elasticity imaging (UEI) $(13,14)$. Given that the fibroblast both induces and responds to mechanical stiffness and that fibrosis can auto-propagate without an inflammatory stimulus, we hypothesized that the stiffness of the cellular environment associated with fibrostenotic disease may alter colonic myofibroblast activation, producing a fibrogenic phenotype and autopropagating fibrosis.

As normal or pathological tissue stiffness varies across organ systems, ex vivo colonic tissue from normal patients, Crohn's strictures, and the unaffected surgical margin were used to determine the physiological stiffness of normal or fibrotic colon for development of an in vitro cell culture model of tissue stiffness(50). CD strictured tissue was nearly 6-fold stiffer than either normal bowel or the unaffected margin. Fibrogenic, matrix remodeling, barrier function, and inflammatory genes were significantly increased in the CD strictured tissue, indicative of concurrent fibrosis and inflammation. To isolate the impact of stiffness on the fibroblast response, a reductionist in vitro stiffness model was utilized to determine the effect of matrix stiffening in the absence of inflammatory or immune signaling.

Human colonic fibroblasts cultured on physiologically stiff matrices corresponding to strictured colon developed a stellate morphology, achieved higher cell density with increased cellular proliferation, and expressed higher aSMA protein levels compared to fibroblasts cultured on physiologically compliant matrices. The fibroblast response to increased matrix stiffness was characterized by a dramatic organization of actin stress fibers and formation of mature focal adhesions. In addition to architectural changes, increased matrix stiffness induced the expression of MYLK, the gene for myosin light chain kinase, which facilitates myosin II binding to actin filaments within the stress fibers (25). While fibroblast contractile activity was not directly assayed, the combined architectural changes and the induction of this mediator of stress fiber contractile activity suggest a mechanism whereby matrix stiffness may promote fibroblast contraction by increasing actin organization and MRTF-A nuclear localization which may upregulate ECM gene expression further increasing the matrix stiffness.

Matrix stiffness and ECM homeostasis are regulated in part by matrix degrading proteins including matrix metalloproteinases (MMPs) (27). In the ex vivo CD strictured tissue, comprised of numerous cell types including epithelial, immune, and fibroblast lineages, MMP-3 expression increased. In vitro, MMP-3, MMP-1, and MMP-10 expression was repressed by increased matrix stiffness and MMP-3 proteolytic activity was repressed, suggesting increased matrix stiffness globally represses matrix degrading function in the fibroblast.

In animal colitis models and human inflammatory bowel disease (IBD), MMP-3, MMP-1, and MMP-10 are upregulated, often in cell types which do not normally produce MMPs under non-inflammatory conditions $(27,51)$. In addition, immune cells including macrophages, mononuclear cells, and lymphocytes are the major producers of MMPs in colitis models or IBD (27). Significant inflammation (as determined by a dramatic increase 
in IL-1 $\beta$ gene expression) was detected in the ex vivo tissue from CD strictures, suggesting an ongoing, active immune response. IL- $1 \beta$ triggers matrix catabolism through activation of MMPs including MMP-3 (29). In turn, MMP-3 activates proMMPs (MMP-1, MMP-7, MMP-2, MMP-9) and degrades ECM proteins including collagens and fibronectin (52). Therefore, repression of IL- $1 \beta$ mediated MMP expression may preserve a pathologically stiff ECM.

In the in vitro stiffness model, devoid of an immune system and inflammatory cells, both IL-1 $\beta$ and PTGS2 (the gene for COX-2 enzyme) expression were repressed by increased matrix stiffness. In lung fibroblasts, matrix stiffening inhibits the endogenous COX-2 inhibitory pathway leading to self-sustaining fibrosis (42). It is tempting to postulate that increased matrix stiffness in the absence of paracrine signaling maintains fibroblast activation by repressing autocrine IL- $1 \beta$ signaling which leads to downstream MMP activation and matrix catabolism. Repression of matrix catabolysis may not only preserve the ECM but actually increase ECM stiffness while inhibition of COX-2 further maintains fibroblast fibrogenic activation.

Fibroblast activation is characterized by increased aSMA protein expression (40). On the physiologically soft matrix, aSMA expression was nearly undetectable. However, on the stiff matrix corresponding to strictured tissue, aSMA protein expression was strongly induced. In cardiomyocytes, aSMA promoter activity is induced by mechanical force mediated by the transcriptional cofactor MRTF-A (43). While modest transcriptional induction of MKL1 (the gene for MRTF-A) occurred in response to high matrix stiffness in the human colonic fibroblasts, MRTF-A nuclear localization was dramatically affected by high matrix stiffness, translocating to the nucleus in a time-dependent manner.

MRTF-A nuclear localization is directly regulated by actin polymerization $(53,54)$. Under conditions of low actin polymerization, inactive MRTF is sequestered in the cytoplasm. As actin polymerizes into actin filaments, MRTF is released and translocates to the nucleus as a transcriptional activator of both aSMA and MYLK (55). Very recent studies in lung fibroblasts demonstrated that MRTF-A transduces mechanical stimuli from the ECM, inducing aSMA expression and myofibroblast differentiation (41). Induction of actin and contractile filament assembly genes by actin polymerization via MRTF-A suggests a role for an auto-regulatory loop whereby substrate mechanical properties are transmitted to the nucleus. A kinetically regulated, actin polymerization auto-feedback loop may explain both the constitutive activation of colonic fibroblasts on a stiff matrix and the in vivo autopropagation of fibrosis.

While this study did not examine specific mechanisms, numerous studies have identified the role of mechanotranduction in cell morphology and function. Mechanical signals from the extracellular matrix are transmitted via multiple signaling pathways including focal adhesion kinase (FAK), Rho/ROCK (Rho-associated protein kinase), and MYLK (17, 41, 56-58). As we demonstrate, pathologically high matrix stiffness induced maturation of focal adhesions in human colonic myofibroblasts, suggesting mechanoactivation occurs through a FAK signaling pathway. However in our experiments, increased matrix stiffness also induced aSMA protein expression, MYLK transcription, and MRTF-A nuclear translocation. As noted by Hinz, et al, aSMA expression, a marker of activated fibroblasts, increases their contractile ability which is essential for wound healing and closure (40). Myofibroblast contractile activation occurs through two complementary pathways, Rho/ROCK and MYLK, which have distinct temporal-spatial roles $(24,49,56,59)$. As we have demonstrated, increased matrix stiffness activated fibroblasts, as evidenced by increased aSMA expression and alteration of actin stress fiber organization, two processes which are mediated by the Rho/ROCK pathway (40). Yet increased matrix stiffness also induced 
MYLK transcription which ultimately regulates aSMA transcription required for stress fiber assembly and subsequent ECM contraction implying that matrix stiffness targets both pathways involved in contractile activation $(25,59,60)$.

In conclusion, we demonstrate that matrix stiffness, similar to the pathological stiffness of Crohn's strictures, activates human colonic fibroblasts to a fibrogenic phenotype. We postulate that multiple cellular pathways contribute to mechanoactivation of fibroblasts including autocrine IL- $1 \beta$ repression of MMPs, suppression of autoinhibitory COX-2, and nuclear localization of MRTF-A. That matrix stiffness affects multiple pathways suggests that the mechanical properties of the cellular environment are critical to fibroblast function and may explain the autopropagation of fibrosis in the absence of inflammation and the intractable intestinal fibrosis characteristic of Crohn's disease.

\section{Supplementary Material}

Refer to Web version on PubMed Central for supplementary material.

\section{Acknowledgments}

We thank Don Powell, Department of Internal Medicine, The University of Texas Medical Branch (Galveston, TX) for the primary human colonic myofibroblast cells, and Claudio Fiocchi and Florian Rieder, Department of Gastroenterology \& Hepatology, Digestive Disease Institute, The Cleveland Clinic (Cleveland, $\mathrm{OH}$ ) for the human intestinal fibroblast cells. This work was funded by a NIH K08DK080172-01 award to P. D. R. H. and a NIH R01HL105489 award to J. C. H.

\section{REFERENCES}

1. Rieder F, Brenmoehl J, Leeb S, et al. Wound healing and fibrosis in intestinal disease. Gut. 2007; 56:130-139. [PubMed: 17172588]

2. Andres PG, Friedman LS. Epidemiology and the natural course of inflammatory bowel disease. Gastroenterol Clin North Am. 1999; 28:255-281. vii. [PubMed: 10372268]

3. Sands BE, Arsenault JE, Rosen MJ, et al. Risk of early surgery for Crohn's disease: implications for early treatment strategies. Am J Gastroenterol. 2003; 98:2712-2718. [PubMed: 14687822]

4. Louis E, Collard A, Oger AF, et al. Behaviour of Crohn's disease according to the Vienna classification: changing pattern over the course of the disease. Gut. 2001; 49:777-782. [PubMed: 11709511]

5. Johnson LA, Luke A, Sauder K, et al. Intestinal fibrosis is reduced by early elimination of inflammation in a mouse model of IBD: Impact of a "Top-Down" approach to intestinal fibrosis in mice. Inflamm Bowel Dis. 2011

6. Powell DW, Mifflin RC, Valentich JD, et al. Myofibroblasts. II. Intestinal subepithelial myofibroblasts. Am J Physiol. 1999; 277:C183-C201. [PubMed: 10444394]

7. Powell DW, Adegboyega PA, Di Mari JF, et al. Epithelial cells and their neighbors I. Role of intestinal myofibroblasts in development, repair, and cancer. Am J Physiol Gastrointest Liver Physiol. 2005; 289:G2-G7. [PubMed: 15961883]

8. Hinz B. Formation and function of the myofibroblast during tissue repair. J Invest Dermatol. 2007; 127:526-537. [PubMed: 17299435]

9. Hinz B, Phan SH, Thannickal VJ, et al. The myofibroblast: one function, multiple origins. Am J Pathol. 2007; 170:1807-1816. [PubMed: 17525249]

10. Wipff PJ, Hinz B. Myofibroblasts work best under stress. J Bodyw Mov Ther. 2009; 13:121-127. [PubMed: 19329048]

11. Pucilowska JB, Williams KL, Lund PK. Fibrogenesis. IV. Fibrosis and inflammatory bowel disease: cellular mediators and animal models. Am J Physiol Gastrointest Liver Physiol. 2000; 279:G653-G659. [PubMed: 11005750]

12. Burke JP, Mulsow JJ, O'Keane C, et al. Fibrogenesis in Crohn's disease. Am J Gastroenterol. 2007; 102:439-448. [PubMed: 17156147] 
13. Kim K, Johnson LA, Jia C, et al. Noninvasive ultrasound elasticity imaging (UEI) of Crohn's disease: animal model. Ultrasound Med Biol. 2008; 34:902-912. [PubMed: 18294759]

14. Stidham RW, Xu J, Johnson LA, et al. Ultrasound elasticity imaging for detecting intestinal fibrosis and inflammation in rats and humans with Crohn's disease. Gastroenterology. 2011; 141:819-826. e811. [PubMed: 21784048]

15. Georges PC, Hui JJ, Gombos Z, et al. Increased stiffness of the rat liver precedes matrix deposition: implications for fibrosis. Am J Physiol Gastrointest Liver Physiol. 2007; 293:G1147G1154. [PubMed: 17932231]

16. Eckes B, Nischt R, Krieg T. Cell-matrix interactions in dermal repair and scarring. Fibrogenesis Tissue Repair. 2010; 3:4. [PubMed: 20222960]

17. Wells RG. The role of matrix stiffness in regulating cell behavior. Hepatology. 2008; 47:13941400. [PubMed: 18307210]

18. Hinz B. The myofibroblast: paradigm for a mechanically active cell. J Biomech. 2010; 43:146155. [PubMed: 19800625]

19. Aplin JD, Hughes RC. Protein-derivatised glass coverslips for the study of cell-to substratum adhesion. Anal Biochem. 1981; 113:144-148. [PubMed: 7023273]

20. Pelham RJ Jr. Wang YL. Cell locomotion and focal adhesions are regulated by the mechanical properties of the substrate. Biol Bull. 1998; 194:348-349. discussion 349-350. [PubMed: 11536880]

21. Tse JR, Engler AJ. Preparation of hydrogel substrates with tunable mechanical properties. Curr Protoc Cell Biol. 2010 Chapter 10:Unit 1016.

22. Erkamp RQ, Wiggins P, Skovoroda AR, et al. Measuring the elastic modulus of small tissue samples. Ultrason Imaging. 1998; 20:17-28. [PubMed: 9664648]

23. Blair SA, Kane SV, Clayburgh DR, et al. Epithelial myosin light chain kinase expression and activity are upregulated in inflammatory bowel disease. Lab Invest. 2006; 86:191-201. [PubMed: 16402035]

24. Russo JM, Florian P, Shen L, et al. Distinct temporal-spatial roles for rho kinase and myosin light chain kinase in epithelial purse-string wound closure. Gastroenterology. 2005; 128:987-1001. [PubMed: 15825080]

25. Vicente-Manzanares M, Ma X, Adelstein RS, et al. Non-muscle myosin II takes centre stage in cell adhesion and migration. Nat Rev Mol Cell Biol. 2009; 10:778-790. [PubMed: 19851336]

26. Hong F, Haldeman BD, Jackson D, et al. Biochemistry of smooth muscle myosin light chain kinase. Arch Biochem Biophys. 2011; 510:135-146. [PubMed: 21565153]

27. Ravi A, Garg P, Sitaraman SV. Matrix metalloproteinases in inflammatory bowel disease: boon or a bane? Inflamm Bowel Dis. 2007; 13:97-107. [PubMed: 17206645]

28. Salmela MT, Pender SL, Karjalainen-Lindsberg ML, et al. Collagenase-1 (MMP-1), matrilysin-1 (MMP-7), and stromelysin-2 (MMP-10) are expressed by migrating enterocytes during intestinal wound healing. Scand J Gastroenterol. 2004; 39:1095-1104. [PubMed: 15545168]

29. Bamba S, Andoh A, Yasui H, et al. Matrix metalloproteinase-3 secretion from human colonic subepithelial myofibroblasts: role of interleukin-17. J Gastroenterol. 2003; 38:548-554. [PubMed: 12825130]

30. Andoh A, Bamba S, Fujiyama Y, et al. Colonic subepithelial myofibroblasts in mucosal inflammation and repair: contribution of bone marrow-derived stem cells to the gut regenerative response. J Gastroenterol. 2005; 40:1089-1099. [PubMed: 16378172]

31. Hiramitsu T, Yasuda T, Ito H, et al. Intercellular adhesion molecule-1 mediates the inhibitory effects of hyaluronan on interleukin-1beta-induced matrix metalloproteinase production in rheumatoid synovial fibroblasts via down-regulation of NF-kappaB and p38. Rheumatology (Oxford). 2006; 45:824-832. [PubMed: 16449361]

32. Zhang HY, Phan SH. Inhibition of myofibroblast apoptosis by transforming growth factor beta(1). Am J Respir Cell Mol Biol. 1999; 21:658-665. [PubMed: 10572062]

33. Kaur H, Chaurasia SS, Agrawal V, et al. Corneal myofibroblast viability: opposing effects of IL-1 and TGF beta1. Exp Eye Res. 2009; 89:152-158. [PubMed: 19285499] 
34. Zhang HY, Gharaee-Kermani M, Phan SH. Regulation of lung fibroblast alpha-smooth muscle actin expression, contractile phenotype, and apoptosis by IL-1beta. J Immunol. 1997; 158:13921399. [PubMed: 9013984]

35. Mifflin RC, Saada JI, Di Mari JF, et al. Regulation of COX-2 expression in human intestinal myofibroblasts: mechanisms of IL-1-mediated induction. Am J Physiol Cell Physiol. 2002; 282:C824-C834. [PubMed: 11880271]

36. Hinterleitner TA, Saada JI, Berschneider HM, et al. IL-1 stimulates intestinal myofibroblast COX gene expression and augments activation of Cl- secretion in T84 cells. Am J Physiol. 1996; 271:C1262-C1268. [PubMed: 8897833]

37. Lama V, Moore BB, Christensen P, et al. Prostaglandin E2 synthesis and suppression of fibroblast proliferation by alveolar epithelial cells is cyclooxygenase-2-dependent. Am J Respir Cell Mol Biol. 2002; 27:752-758. [PubMed: 12444036]

38. Huang S, Wettlaufer SH, Hogaboam C, et al. Prostaglandin E(2) inhibits collagen expression and proliferation in patient-derived normal lung fibroblasts via $\mathrm{E}$ prostanoid 2 receptor and cAMP signaling. Am J Physiol Lung Cell Mol Physiol. 2007; 292:L405-L413. [PubMed: 17028262]

39. Eckes B, Zweers MC, Zhang ZG, et al. Mechanical tension and integrin alpha 2 beta 1 regulate fibroblast functions. J Investig Dermatol Symp Proc. 2006; 11:66-72.

40. Hinz B, Celetta G, Tomasek JJ, et al. Alpha-smooth muscle actin expression upregulates fibroblast contractile activity. Mol Biol Cell. 2001; 12:2730-2741. [PubMed: 11553712]

41. Huang X, Yang N, Fiore VF, et al. Matrix Stiffness-Induced Myofibroblast Differentiation Is Mediated by Intrinsic Mechanotransduction. Am J Respir Cell Mol Biol. 2012

42. Liu F, Mih JD, Shea BS, et al. Feedback amplification of fibrosis through matrix stiffening and COX-2 suppression. J Cell Biol. 2010; 190:693-706. [PubMed: 20733059]

43. Zhao XH, Laschinger C, Arora P, et al. Force activates smooth muscle alpha-actin promoter activity through the Rho signaling pathway. J Cell Sci. 2007; 120:1801-1809. [PubMed: 17456553]

44. Pipes GC, Creemers EE, Olson EN. The myocardin family of transcriptional coactivators: versatile regulators of cell growth, migration, and myogenesis. Genes Dev. 2006; 20:1545-1556. [PubMed: 16778073]

45. Cosnes J. Can we modulate the clinical course of inflammatory bowel diseases by our current treatment strategies? Dig Dis. 2009; 27:516-521. [PubMed: 19897968]

46. Jones DW, Finlayson SR. Trends in surgery for Crohn's disease in the era of infliximab. Ann Surg. 2010; 252:307-312. [PubMed: 20585239]

47. Cosnes J, Cattan S, Blain A, et al. Long-term evolution of disease behavior of Crohn's disease. Inflamm Bowel Dis. 2002; 8:244-250. [PubMed: 12131607]

48. Vermeire S, van Assche G, Rutgeerts P. Review article: Altering the natural history of Crohn's disease--evidence for and against current therapies. Aliment Pharmacol Ther. 2007; 25:3-12. [PubMed: 17229216]

49. Tomasek JJ, Gabbiani G, Hinz B, et al. Myofibroblasts and mechano-regulation of connective tissue remodelling. Nat Rev Mol Cell Biol. 2002; 3:349-363. [PubMed: 11988769]

50. Hinz B. Tissue stiffness, latent TGF-beta1 activation, and mechanical signal transduction: implications for the pathogenesis and treatment of fibrosis. Curr Rheumatol Rep. 2009; 11:120 126. [PubMed: 19296884]

51. Baugh MD, Perry MJ, Hollander AP, et al. Matrix metalloproteinase levels are elevated in inflammatory bowel disease. Gastroenterology. 1999; 117:814-822. [PubMed: 10500063]

52. Chakraborti S, Mandal M, Das S, et al. Regulation of matrix metalloproteinases: an overview. Mol Cell Biochem. 2003; 253:269-285. [PubMed: 14619979]

53. Olson EN, Nordheim A. Linking actin dynamics and gene transcription to drive cellular motile functions. Nat Rev Mol Cell Biol. 2010; 11:353-365. [PubMed: 20414257]

54. Miralles F, Posern G, Zaromytidou AI, et al. Actin dynamics control SRF activity by regulation of its coactivator MAL. Cell. 2003; 113:329-342. [PubMed: 12732141]

55. Wang D, Chang PS, Wang Z, et al. Activation of cardiac gene expression by myocardin, a transcriptional cofactor for serum response factor. Cell. 2001; 105:851-862. [PubMed: 11439182] 
56. Castella LF, Buscemi L, Godbout C, et al. A new lock-step mechanism of matrix remodelling based on subcellular contractile events. J Cell Sci. 2010; 123:1751-1760. [PubMed: 20427321]

57. Chen CS. Mechanotransduction - a field pulling together? J Cell Sci. 2008; 121:3285-3292. [PubMed: 18843115]

58. Guan JL. Role of focal adhesion kinase in integrin signaling. Int J Biochem Cell Biol. 1997; 29:1085-1096. [PubMed: 9416004]

59. Katoh K, Kano Y, Amano M, et al. Stress fiber organization regulated by MLCK and Rho-kinase in cultured human fibroblasts. Am J Physiol Cell Physiol. 2001; 280:C1669-C1679. [PubMed: 11350763]

60. Follonier Castella L, Gabbiani G, McCulloch CA, et al. Regulation of myofibroblast activities: calcium pulls some strings behind the scene. Exp Cell Res. 2010; 316:2390-2401. [PubMed: 20451515] 
A

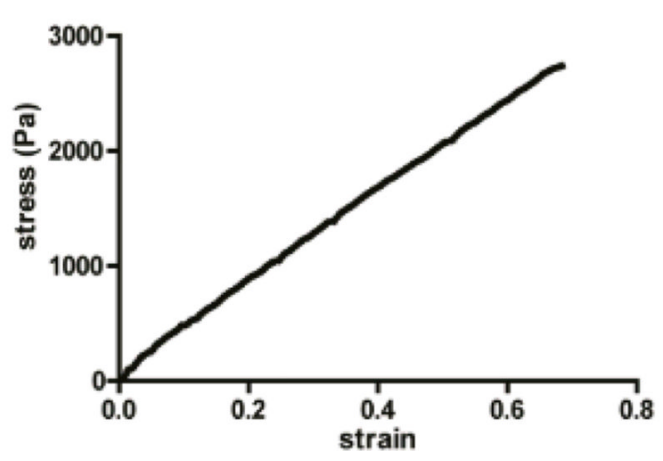

C

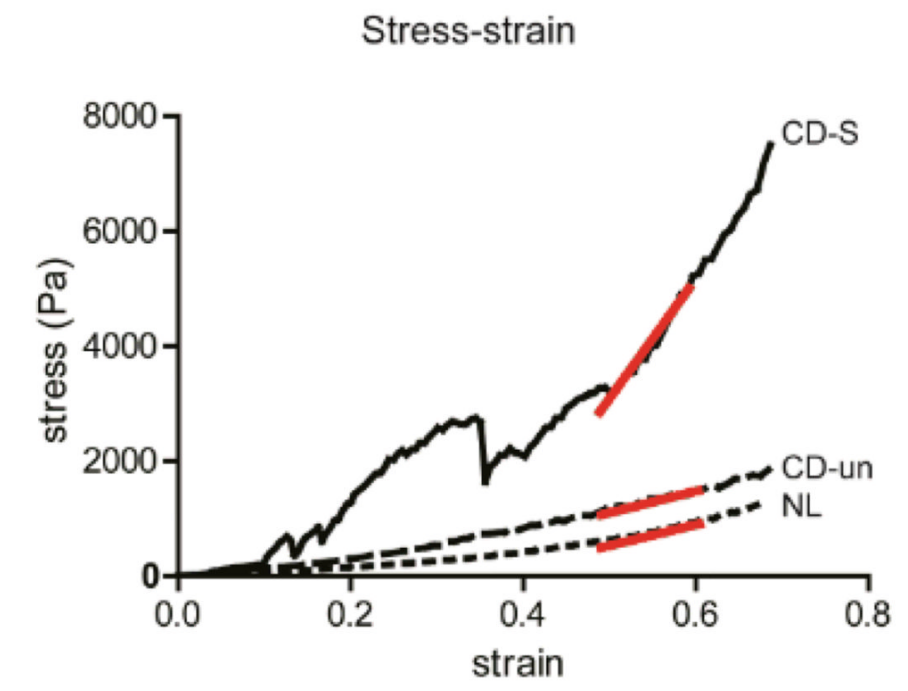

$28 \mathrm{kPa}$

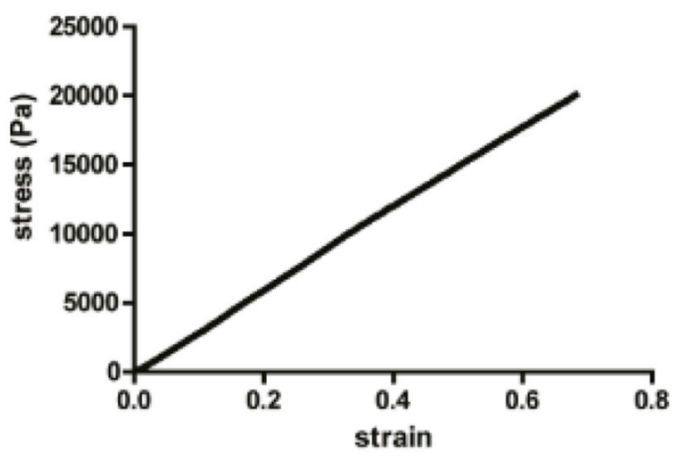

D

$$
E=\frac{\sigma}{\varepsilon}=\frac{\mathrm{FL}_{0}}{\mathrm{~A}_{0} \Delta \mathrm{L}}
$$
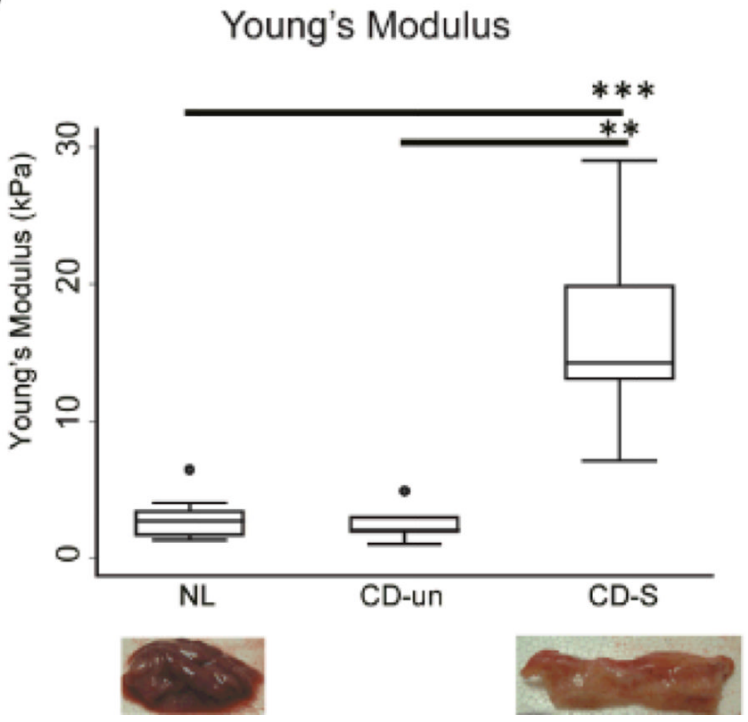

Figure 1. Mechanical characteristics of polyacrylamide stiffness gels and human ex vivo tissue samples from Crohn's strictures, the unaffected margin, or normal human intestine

(A) Stress-strain curves of collagen-coated polyacrylamide gels corresponding to low (3 $\mathrm{kPa}$ ) and high (28 kPa) elastic moduli. (B) Mathematical formula for the Young's Modulus calculation where $\mathrm{E}=$ Young's Modulus, $\mathrm{F}=$ the force applied to the material, $\mathrm{A}_{0}=$ the cross-section area through which the force was applied to the material, $\Delta \mathrm{L}=$ amount the length of the material changes when the force is applied, $\mathrm{L}_{0}=$ original length of the material (before the force was applied). (C) Representative stress-strain curves of ex vivo normal bowel (NL, dashed line) compared to a Crohn's ex vivo tissue section of stricture (CD-S, solid line) or the margin adjacent to the stricture (CD-un, dotted line). The stricture and margin are from the same resected specimen. Normalized strain was calculated from the linear range between the first and second inflection points on the stress-strain graph (50$60 \%$ of the strain value) as indicated by the red line. (D) Normalized strain values of ex vivo small intestine demonstrating tissue elastic moduli of normal $(\mathrm{NL}, \mathrm{n}=5)$ compared to Crohn's stricture (CD-S, $\mathrm{n}=11$ ) and the unaffected margin (CD-un, $\mathrm{n}=11$ ). Representative photos of the ex vivo tissue samples are shown below the graph. The horizontal line in the box plot represents the median, the upper and lower box boundaries represent the interquartile range, and the ends of the whiskers represent the 5\% and $95 \%$ confidence limits. Extreme values (> 2 standard deviations) are represented as individual dots. 
Horizontal bars denote statistical comparisons between normal tissue and CD-S or comparisons between CD-S and CD-un. Representative photos of normal colon compared to strictured colon are shown below the graph. $(* * \mathrm{p}<0.01, * * * \mathrm{p}<0.001$ compared to normal bowel) 
A

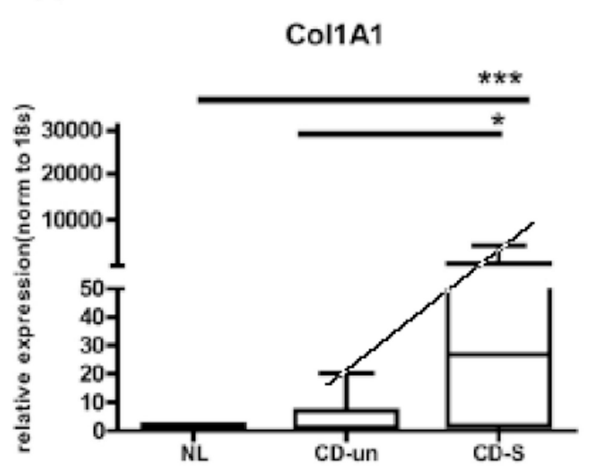

D

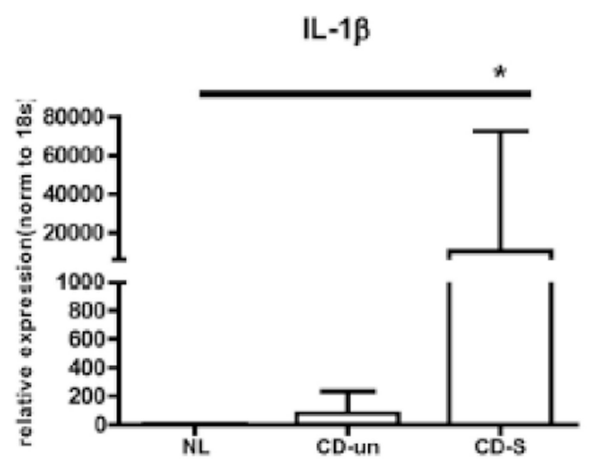

B

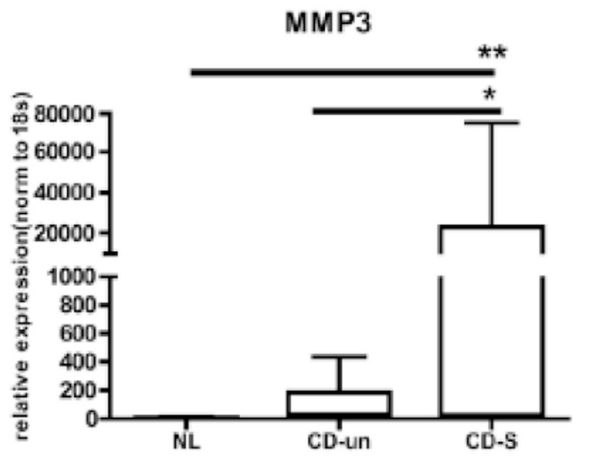

E
C

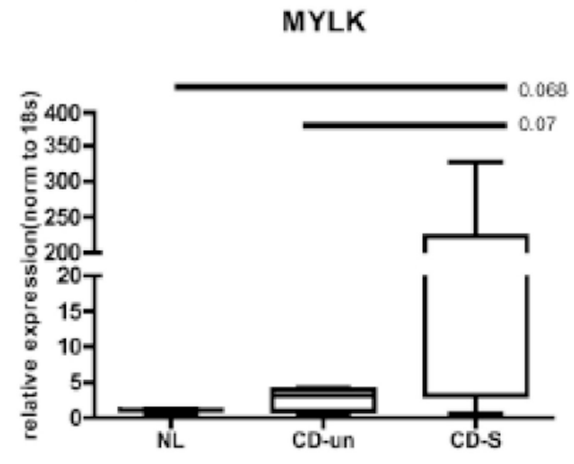

Figure 2. Expression of extracellular matrix and matrix remodeling genes are increased in Crohn's strictures compared to the unaffected margin or normal human intestine (A-E) QRT-PCR gene expression of normal bowel (NL), Crohn's stricture (CD-S) or the margin adjacent to the stricture (CD-un) from FFPE samples of the same patients. (A) Col1A1 (B) MMP-3, (C) MYLK (D) IL-1 $\beta$ (E) PTGS2. Statistical comparisons between the groups are denoted with an asterisk. Horizontal bars denote statistical comparisons between normal tissue and CD-S or comparisons between CD-S and CD-un. (* p <0.05, *** $\mathrm{p}<$ 0.001 compared to normal bowel) 

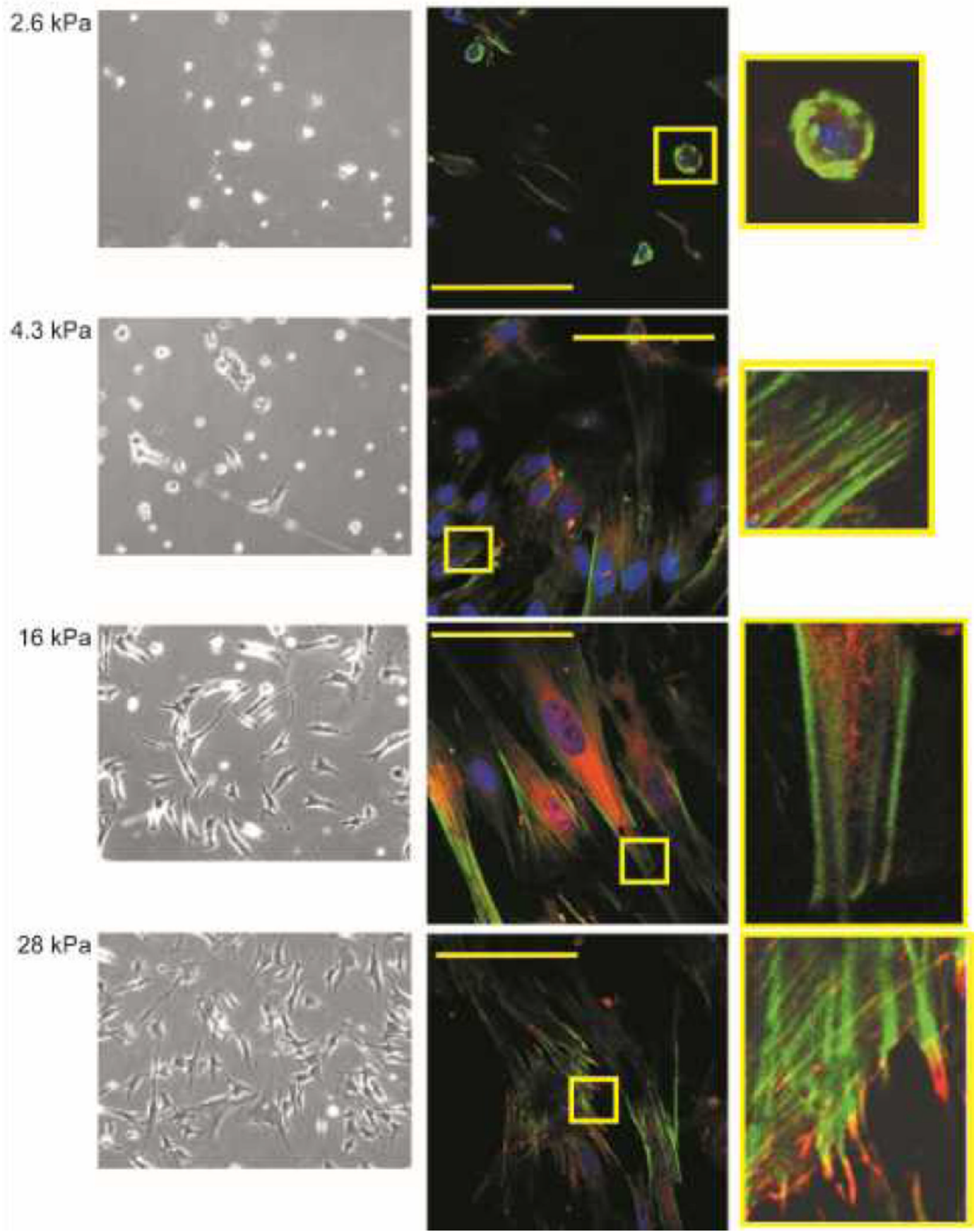

Figure 3. Increasing matrix stiffness alters fibroblast morphology and actin stress fiber accumulation

Ccd-18co colonic fibroblasts were cultured on collagen-coated acrylamide gels of elastic moduli corresponding to normal $(2.6-4.3 \mathrm{kPa})$ or strictured $(16-28 \mathrm{kPa})$ bowel. (Left panel) Phase contrast micrographs (100× magnification) of Ccd-18co cells cultured on increasing matrix stiffness after $24 \mathrm{hr}$ in culture, demonstrating morphological transition from rounded to activated, stellate morphology. Cells were plated at equal densities. (Middle panel) Confocal micrographs (600× magnification) of Ccd-18co cells plated on increasing matrix stiffness. Increased matrix stiffness induces accumulation of actin stress fibers (green) and focal adhesions (vinculin staining, red). Nuclei were visualized with DAPI (blue). Yellow 
scale bar represents $100 \mu \mathrm{m}$. Insets which are shown in detail (right panel) are indicated by yellow boxes. (Right panel) Insets from the confocal images, detailing focal adhesion staining. All inserts are the same magnification. 

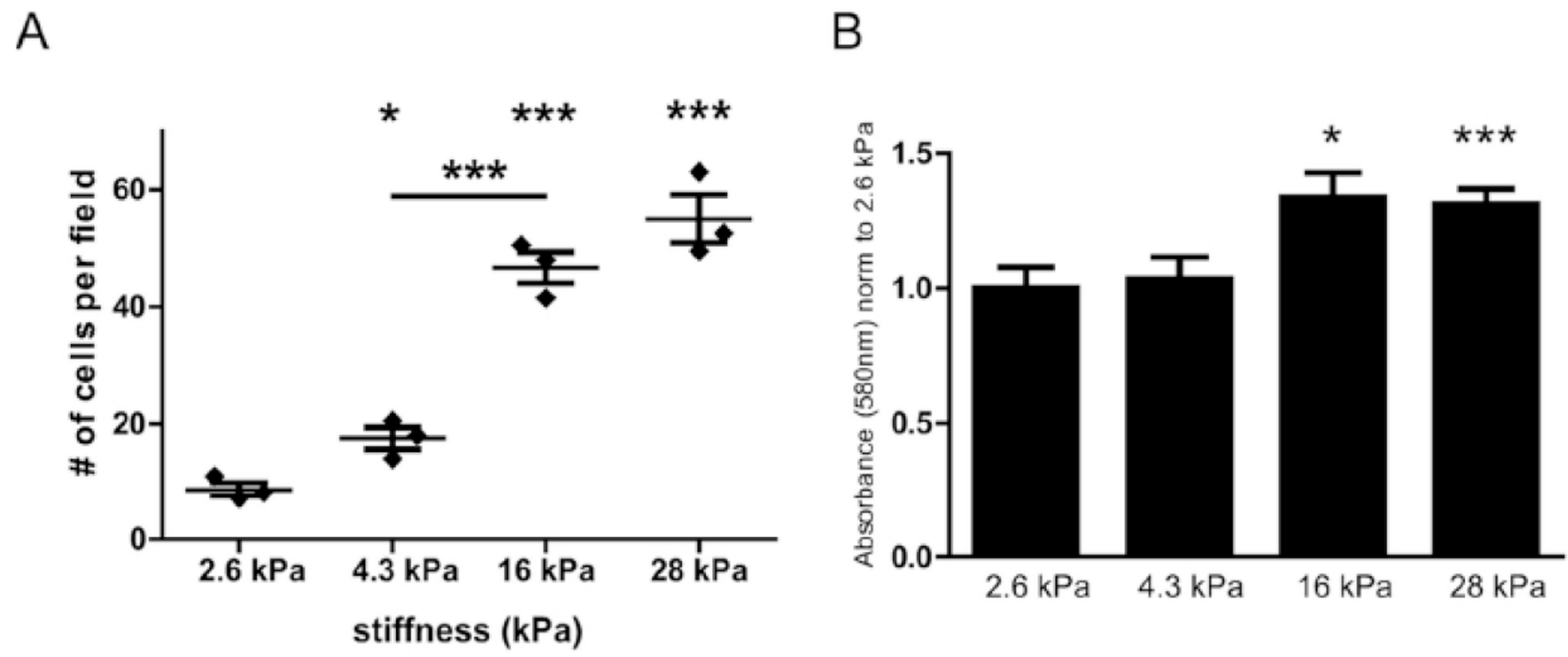

Figure 4. Increased matrix stiffness increases cell number and induces fibroblast proliferation (A) Ccd-18co cell density increases in response to increased matrix stiffness. Cell density was determined from three 100x-magnifcation fields per matrix stiffness and graphed. Individual points represent biologically independent experiments while the horizontal represents the mean for each matrix stiffness. The horizontal bar denotes statistical comparisons between the transition point between soft $(4.3 \mathrm{kPa})$ and stiff (16 kPa). (B) MTT cell proliferation assay of Ccd-18co cells cultured on low $(2.3$ and $4.6 \mathrm{kPa})$ or high $(16 \mathrm{kPa}$ and $28 \mathrm{kPa}$ ) matrix stiffness. Results are from 3 independent experiments with multiple replicates per experiment. $(* \mathrm{p}<0.05$, **p $<0.01$, *** $\mathrm{p}<0.001$ compared to the $2.6 \mathrm{kPa}$ elastic modulus) 
A

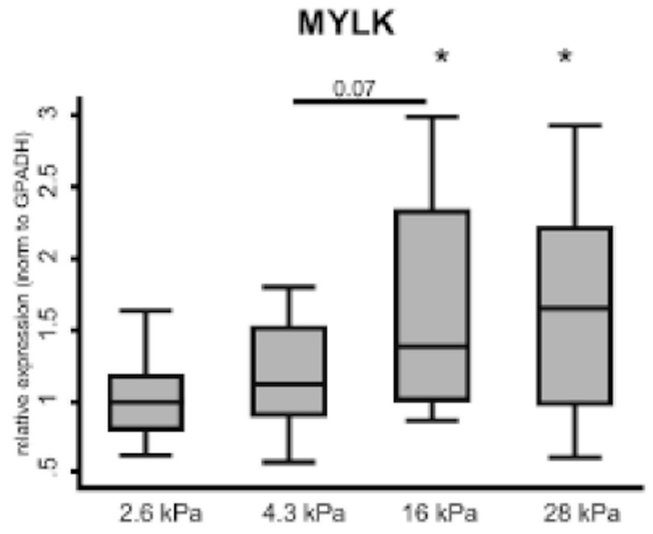

B

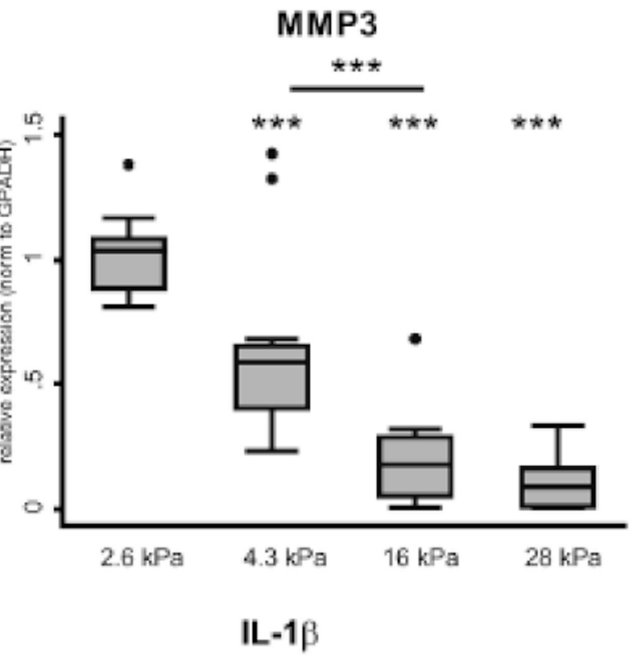

C

MMP1

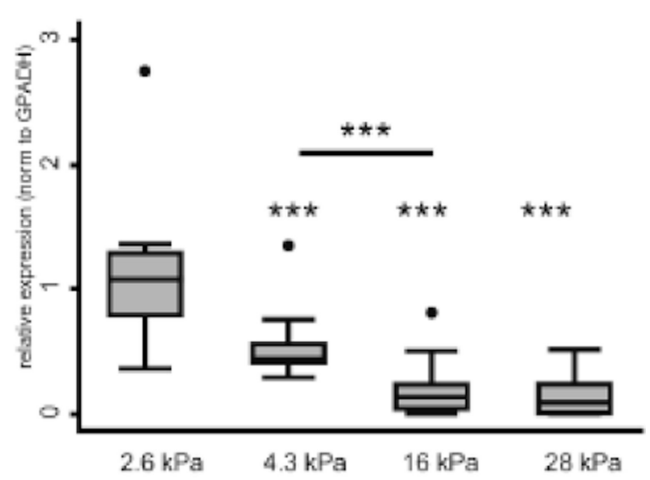

E

PTGS2 (COX-2)
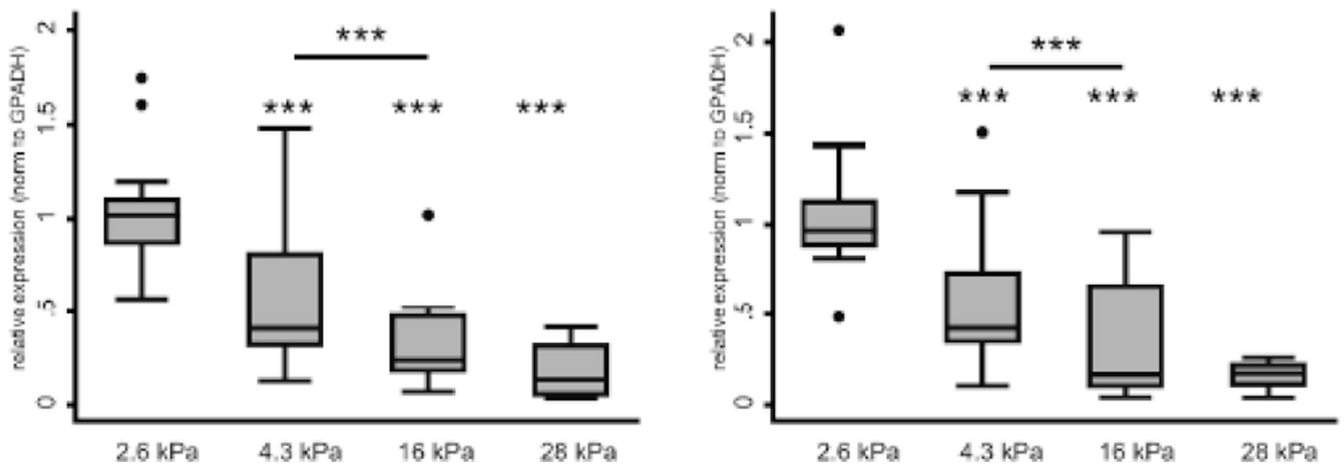

Figure 5. Increasing matrix stiffness induces myosin light chain kinase (MYLK) and represses matrix turnover gene expression

Increasing matrix elastic moduli from 2.6 to $28 \mathrm{kPa}$ induces MYLK gene expression (A), represses matrixmetalloproteinase expression (MMP3 (B)), MMP1(C)), and represses inflammatory gene expression (IL-1 $\beta$ (D) and PTGS2 (E)) in Ccd-18co cells. Horizontal bars denote statistical comparisons between the transition point between soft $(4.3 \mathrm{kPa})$ and stiff $(16 \mathrm{kPa}) .(* * * \mathrm{p}<0.001$ compared to the $4.3 \mathrm{kPa}$ elastic modulus) 
A

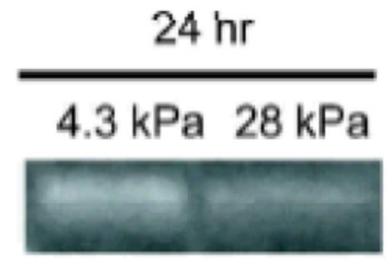

$72 \mathrm{hr}$
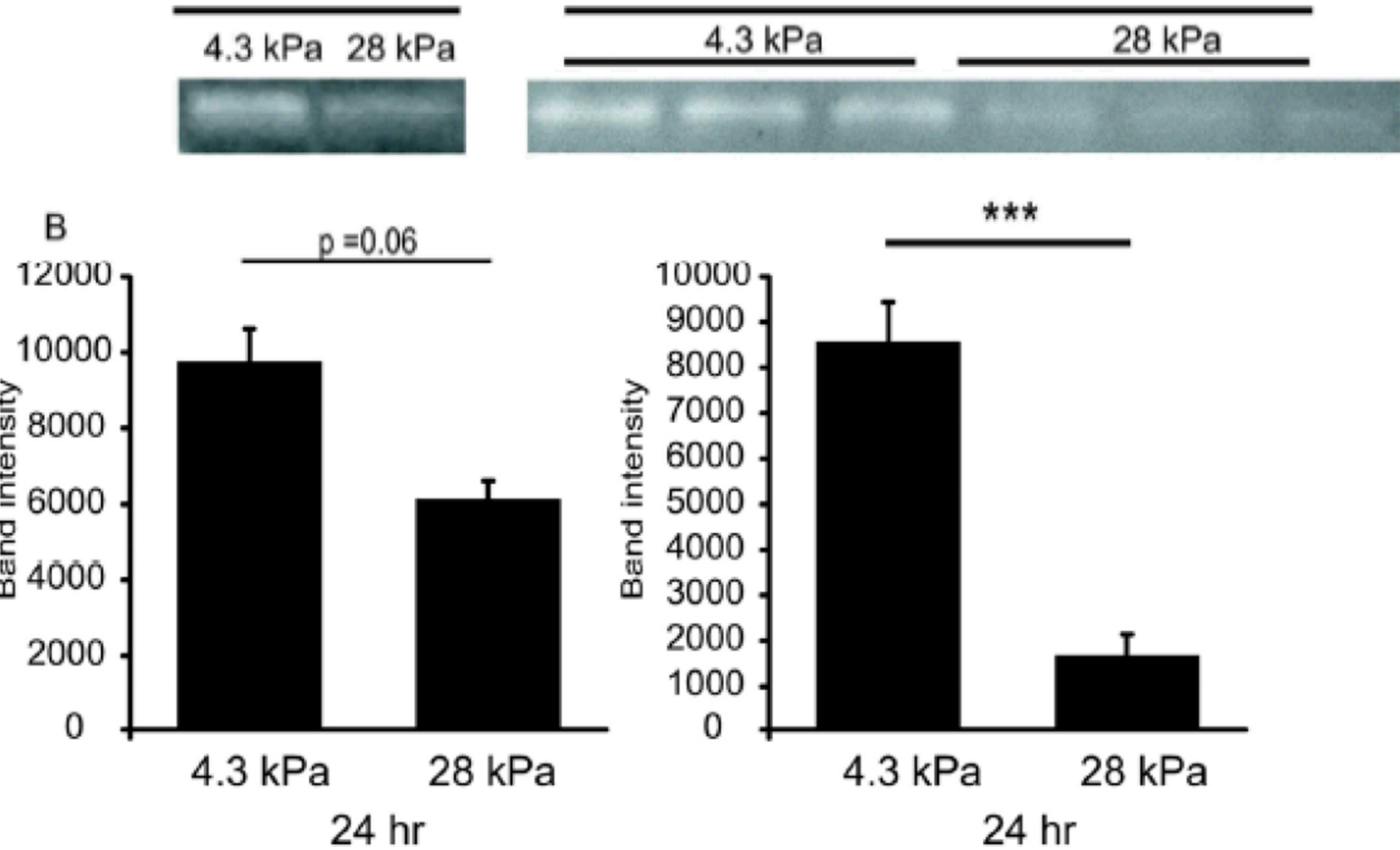

Figure 6. MMP-3 proteolytic activity is repressed by high matrix stiffness

(A) Representative zymographs of MMP-3 caseinolytic activity in culture supernatants from Ccd-18co cells cultured for 24 or 72 hours on soft $(4.3 \mathrm{kPa})$ or stiff $(28 \mathrm{kPa})$ matrices. (B) Densitrometric analysis from 3 independent experiments demonstrating MMP-3 proteolytic activity decreases over time in cells cultured on the stiff matrix. $(* * * p<0.001)$ 
A

soft $4.3 \mathrm{kPa}$

\section{aSMA}

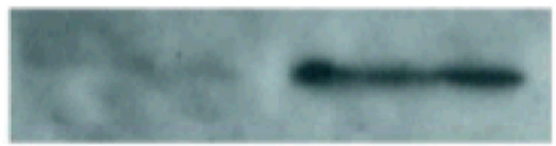

GAPDH

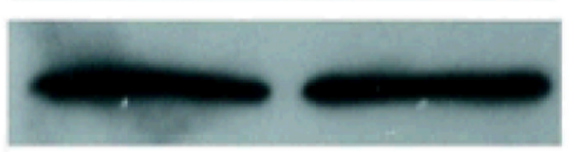

B

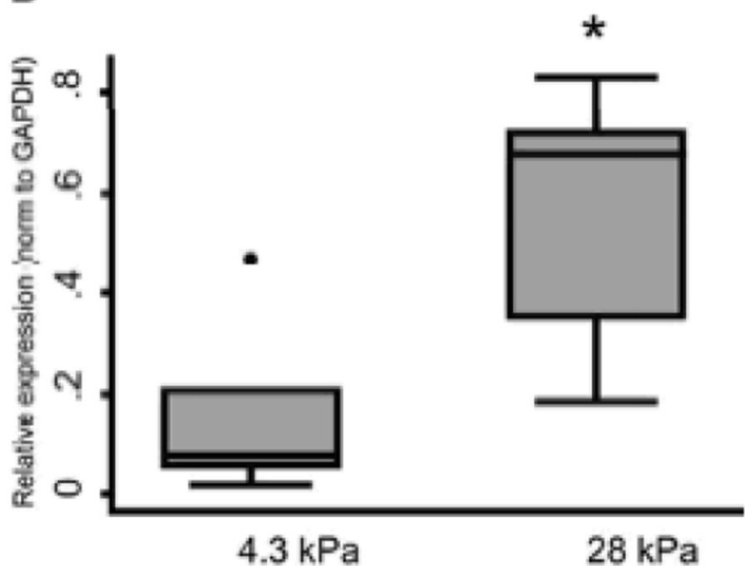

Figure 7. Fibroblast activation by increased matrix stiffness is associated with increased aSMA protein expression

(A) A representative Western illustrating aSMA protein expression of Ccd-18co colonic fibroblasts cultured on soft or stiff matrices for $24 \mathrm{hr}$. GAPDH is shown as protein loading control. (B) Densitrometric analysis of aSMA protein expression of Ccd-18co fibroblasts in response to increased matrix stiffness. Results are from 3 independent experiments with a total of 5 biological replicates. $(* \mathrm{p}<0.05)$ 
A
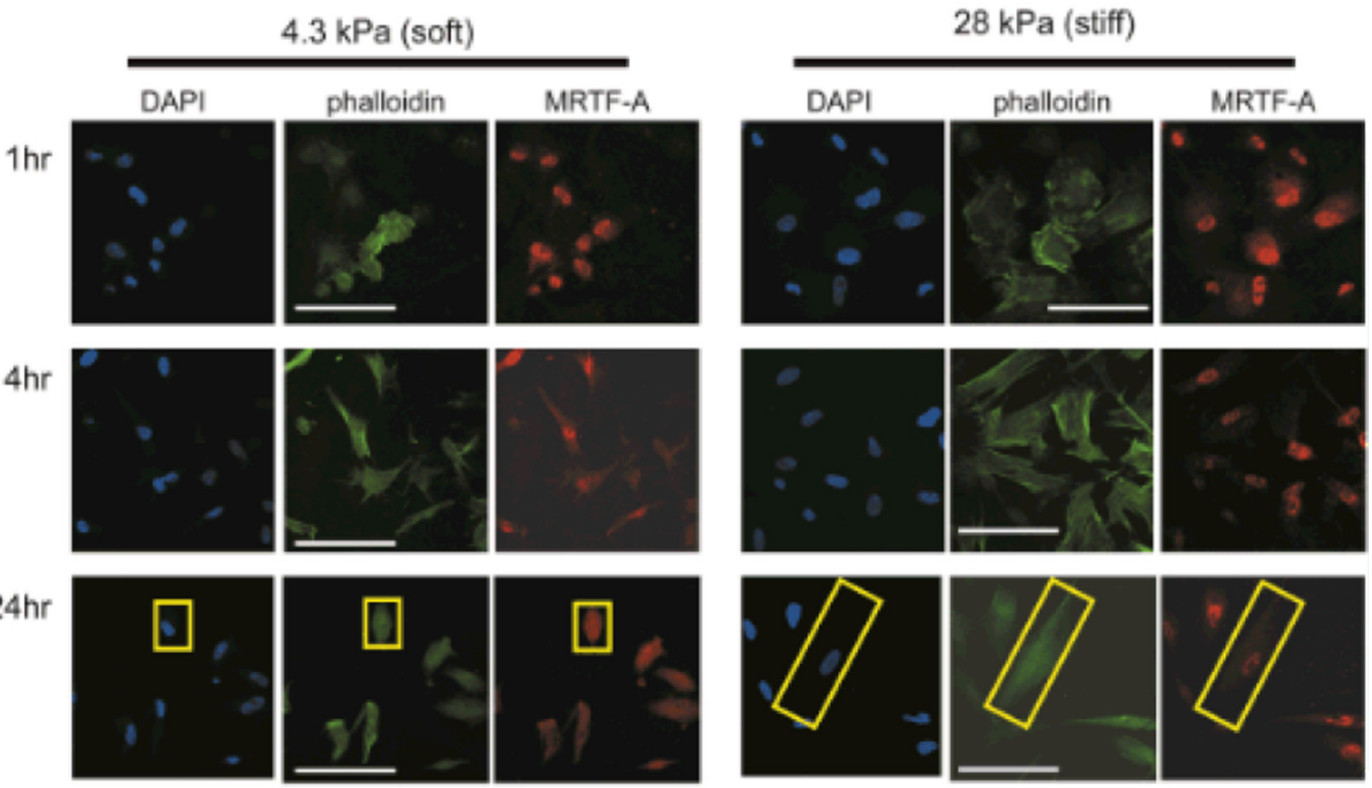

B

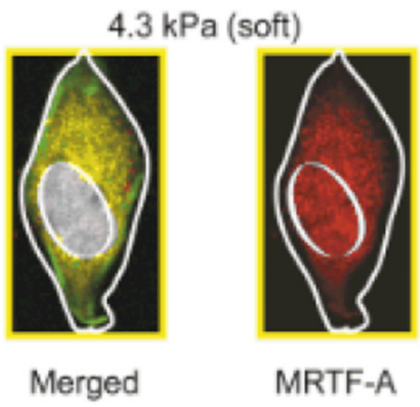

C
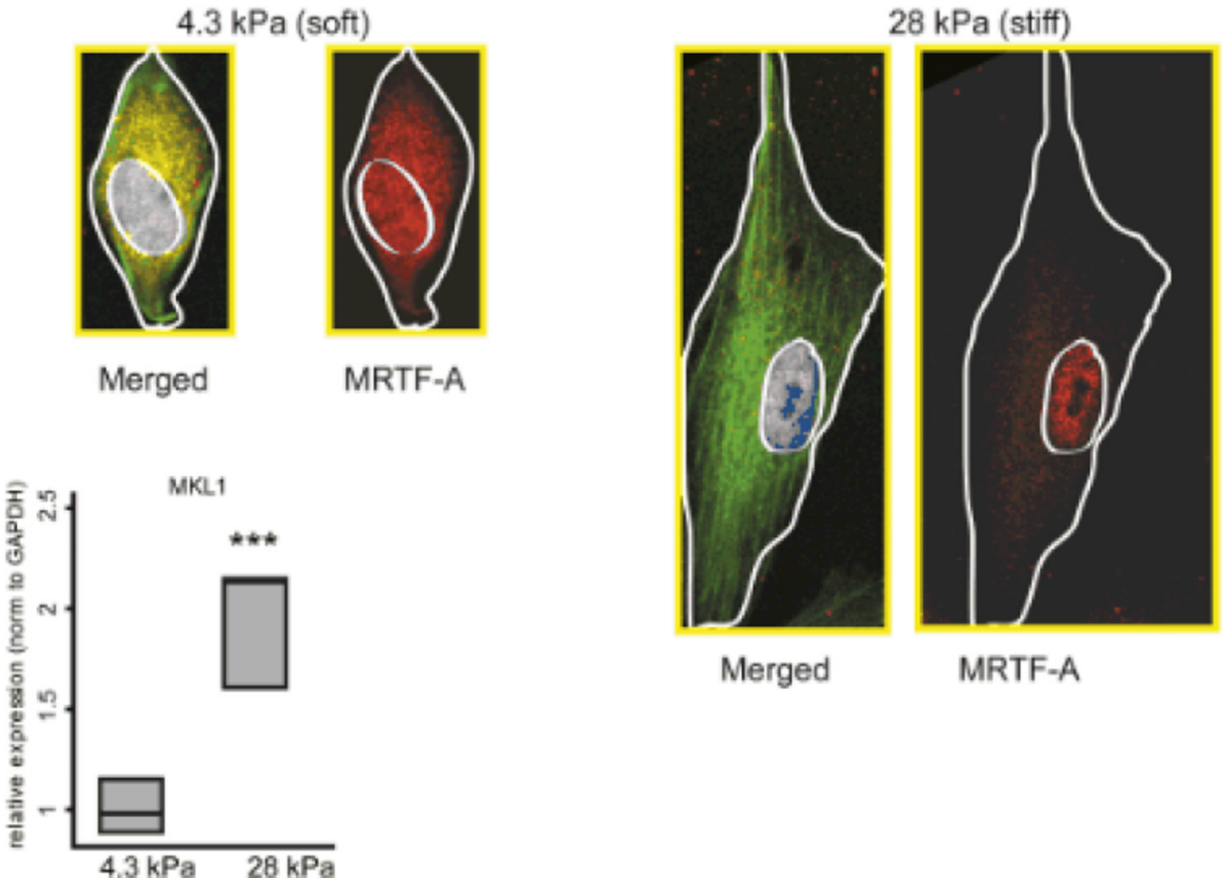

Figure 8. Increased matrix stiffness induces MKL1 (MRTF-A) transcription and promotes MRTF-A nuclear translocation

(A) Immunostaining for MRTF-A localization (red) and actin-stress fibers (green) in Ccd-18co cells cultured for 1, 4, and 24 hours on soft (4.3 kPa, left panel) or stiff (28 kPa, right panel) matrices. Nuclei are identified by DAPI staining (blue). The white scale bar represents $100 \mu \mathrm{m}$. Representative images are shown. (600× magnification). (B) Insets of individual cells cultured for 24 hours (identified by yellow boxes in (A)) demonstrating MRTF-A localization relative to the nucleus and cell membrane (outlined in white). The merged MRTF-A/actin/DAPI image is shown in comparison to the MRTF-A 
immunostaining. Insets are the same magnification. (C) MKL1 (MRTF-A) gene expression in Ccd-18co cells cultured on soft $(4.3 \mathrm{kPa})$ or stiff $(28 \mathrm{kPa})$ matrices. $(* * * \mathrm{p}<0.001)$ 